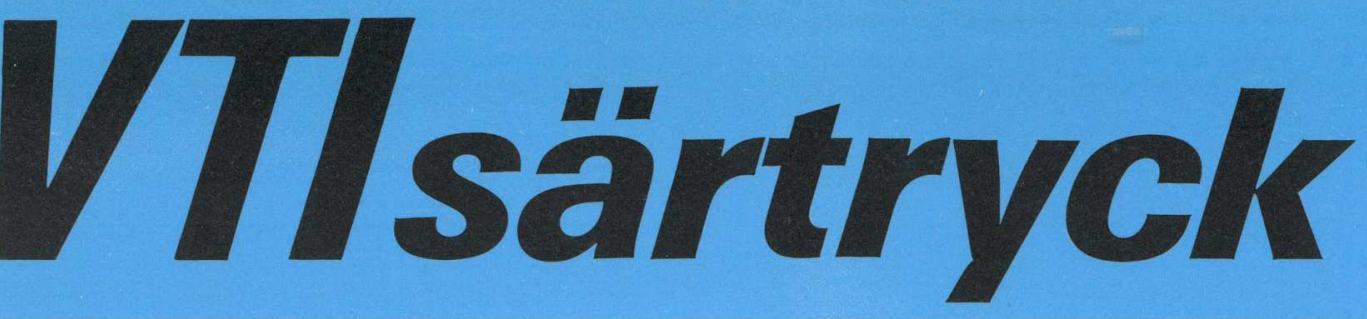

\title{
The basic driver error: late detection
}

\section{Kåre Rumar}

Reprint from Ergonomics, 1990, Vol. 33, Nos 10/11, pp 1 281-1 290 


\title{
The basic driver error: late detection
}

\author{
KÅRE RuMAR \\ Swedish Road and Traffic Research Institute (VTI), \\ S-581 01 Linköping, Sweden
}

Keywords: Human error; Driver behaviour; Attention; Accident prevention.

\begin{abstract}
Over the past two or three decades we have been quite successful in reducing injuries of car occupants by the use of energy-absorbing techniques; but we have not been as successful in reducing the risks of having collisions. When drivers are asked why an accident occurred very often they claim that they saw the other road user too late to avoid collision. This paper discusses the basic road user error of failing to see another road user in time, why such errors happen, and how they can be reduced.

A detection error is basic, because without detection no processing of information, no decision process including that road user, takes place. Among the many causes of detection error two of the more important are:

- a lapse of cognitive expectation, illustrated by the failure to scan for a particular class of road user, or to look in the appropriate direction;

- a difficulty with perceptual thresholds, illustrated by the failure to discern the relevant stimuli in lower levels of ambient illumination or in situations where vehicles approach in the peripheral visual field of road users.
\end{abstract}

\section{Background}

One of the most typical characteristics of human behaviour is variability. It is therefore difficult to decide when an error is made; some kind of criteria is needed. As in all other types of human behaviour, intra-individual, as well as inter-individual, variation in driver behaviour is enormous. It is difficult to separate errors from 'normal' variation. Since we have not really been able to define what is characteristic for a good, error-free driver, we cannot specify what is typical for driver errors. It should be acceptable to classify behaviour leading or contributing to a road accident as erroneous. There are of course exceptions, as when a fault suddenly occurs in the vehicle or the road. Normally the driver acts as the operator (and as the only variable element) in driver-vehicle-road system.

This paper considers only detection errors: that is, failure by a road user to detect another road user in time to be able to avoid him or her while successfully completing a planned course of action.

\section{The role of detection in locomotion}

As forms of locomotion, driving and walking differ in quantitative more than qualitative terms. In both cases individuals make very similar uses of sensory input, mainly visual, in order to make their way about while avoiding other moving creatures and stationary objects. However, the roles of driving and walking are played in very different environments. Compare moving by foot in a forest with moving by car on a motorway. The stimulus richness and redundancy is much larger in the forest. We probably need this redundancy to make accurate decisions, and the failure of the road traffic environment to provide this redundancy is probably the reason why it forces us 
to rely on artificial and questionable information sources like road signs. This could be the topic of several papers, but this paper will consider only the central task of detecting (not estimating or judging) other moving objects (road users).

In this respect the correspondence between walking and driving is probably greater - although the targets and motion patterns have to be detected in different environments, against different backgrounds. Due to the higher speeds and larger masses involved, detection of other moving objects during driving is much more important in road traffic than in walking. Detection has to take place earlier if collisions or near collisions are to be avoided.

\section{Road traffic collisions}

According to official statistics (e.g., UN 1986), collisions between road users constitute about two-thirds of all road accidents involving human injury. In the various attempts to analyse the factors behind such accidents using special multidisciplinary accident investigation groups (e.g., Treat 1980), the ranking of the main types of human errors is

1. recognition errors;

2. decision errors;

3. performance errors;

4. other.

Recognition errors are predominant. These types of errors could be assembled under the heading of 'inappropriate information acquisition and processing'. The next step in the Treat study was to specify the human errors further. In decreasing order of frequency of occurrence the following errors are given:

1. improper lookout;

2. excessive speed;

3. inattention;

4. false assumption;

5. improper manoeuvre;

6. internal distraction.

Here the weakness of this approach becomes evident. Since this, and most previous accident investigations, lack an explicit theoretical basis, the results tend to be of a very general, commonsense, character; they are hard to relate to other types of data, they are hard to communicate to other disciplines, and, perhaps most important, they tend to use human error as an all-purpose default category. Every accident which cannot be explained in terms of technical failures tends to be attributed to human error.

In road traffic with a considerable physical and human inertia it is obvious that failure to detect the other road user early enough is a main source of error. This conclusion is also supported by explanations of their traffic accidents which people give in court. The most frequent explanations for such accidents is 'I saw him too late', 'Suddenly he was there', etc.

\section{Late detection categories}

Failures to detect another road user early enough to avoid a collision may have several causes, but they seem to belong to two main categories:

- a cognitive error, illustrated by a failure to look in the direction of the road user in question, or failure to look for the specific type of road user type in question;

- a perceptual error, illustrated by the failure to detect another road user in peripheral vision or in situations of reduced ambient illumination. 


\section{Cognitive detection errors}

Although our peripheral vision is quite sensitive to motion, human vision is basically a very selective sensory system. When we want to check a real life situation visually we usually cannot look at everything at once. The richness of the visual stimulus pattern is so enormous in its range that perceptual analysis has to be quite selective. We therefore search specific areas of interest where we believe that the information content and density is especially high. We could even express it in the following way: the main task of vision is to test the hypotheses worked out by the subject concerning the situation at the moment and the way the situation is going to change. Experience and expectation guide attention and visual focus. Analyses of patterns of eye movements support these ideas for drivers, as well as for other operators in dynamic situations.

If we use the type of hierarchical driver models (see figure 1) as suggested by Janssen (1979) and others, we may describe the problem of cognitive detection errors in the following way. In the ecological situation of animals in their natural environment, e.g. a person walking in the forest, detection of other moving object (friends, enemies, targets) is normally taking place on the so-called automatic control level. Detection is more or less unconscious, automatic, and fast. By instinct and experience people know what to look for, where, and when to look for it; and if they miss it they have a visual perceptual system developed to detect and compensate for such misses. This makes detection both fast and effective. Furthermore, in general, the speeds and masses are relatively low so that mistakes due to late detection can usually be corrected in time.

Unfortunately today's road users are not protected by evolutionary adaptation to their new, artifical environment, and often have only limited experience of operating within it. The attention, the focus of interest, must often be directed voluntarily in a conscious, planned, and controlled way. Let us take an example. According to the rules of the road, the critical vehicle often appears from the right (the right hand rule in most countries with right hand driving). The search patterns learned and used to detect oncoming vehicles on roads are not automatic and skill-based, but controlled and rulebased (Rasmussen 1980). They are not as efficient and quick as natural skill-based

Time Constant

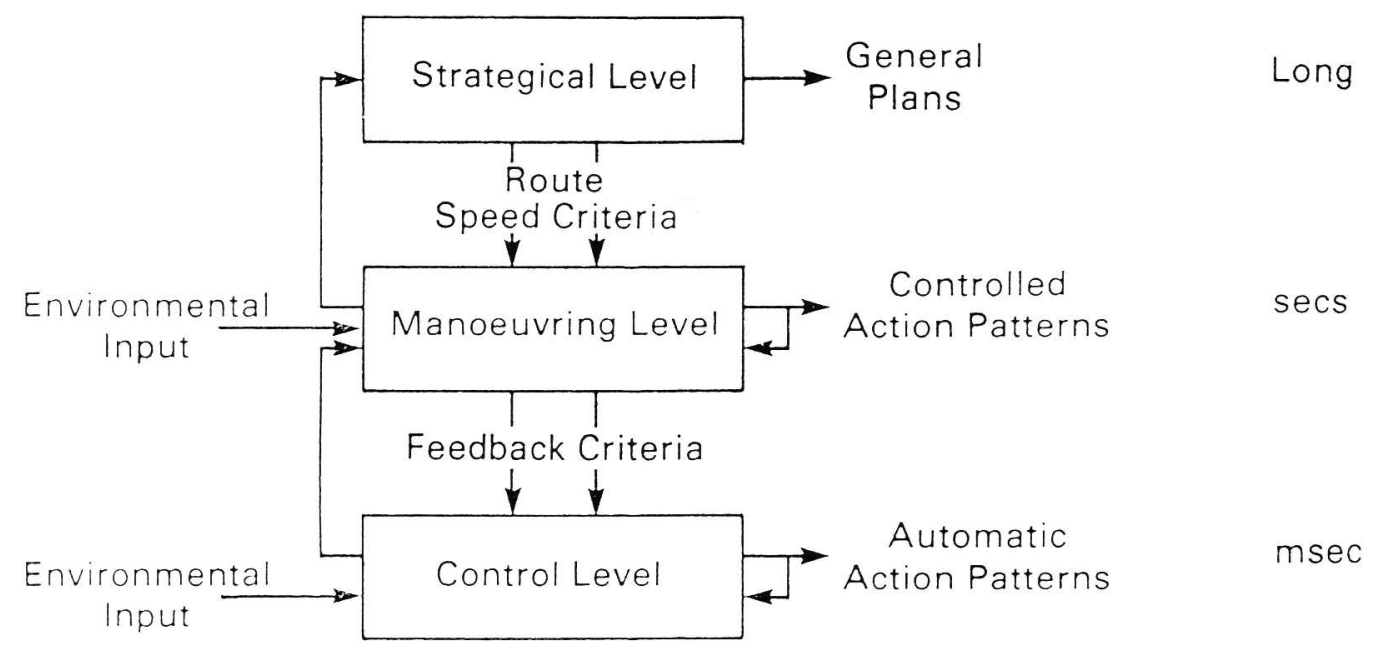

Figure 1. The hierarchical structure of the road user task. Performance is structured at three levels that are comparatively loosely coupled. Internal and external outputs as indicated (after Janssen 1979). 
patterns. They are more vulnerable to errors, and due to the speeds and the masses involved it is very difficult to compensate for an error once it begins to occur. Errors are thus both more probable and more difficult to overcome.

There are situations where the natural skill-based behaviour is in direct conflict with the rule- or knowledge-based, officially-required behaviour. Knowledge, expectation, and behaviour at various types of crossings are illustrative examples (see table 1, Helmers and Åberg 1978). Such clear or contradictory traffic conditions, of course, increase the probability of an error occurring, both for natural and automatic as well as controlled and rule or knowledge based detection errors.

Another detection error of cognitive aetiology occurs when a road user has a partly correct expectation. He or she has a functional model of the traffic which is appropriate in terms of when and where to look, but inappropriate in terms of what to look for. That is, a model which is correct in spatial and temporal relationships but wrong in terms of target selection. The road accident history is full of such examples. Road users usually look in the appropriate direction at the appropriate moment, but they also usually look for cars. This is a very natural behaviour since cars are often the largest, heaviest, fastest, and consequently most dangerous moving object visible. Unfortunately, after doing this and seeing no car within a critical distance, they complete the action they had planned and hit or are hit by a cyclist, a motorcyclist or

Table 1. Results of driver knowledge (\%) about correct behavioural and actual driver behaviour $(\%)$ in four types of intersections.

Type of intersection

\begin{tabular}{|c|c|c|c|c|}
\hline \multirow[t]{2}{*}{ Signed: Right of Way } & \multicolumn{4}{|c|}{ Behaviour } \\
\hline & & + & - & \\
\hline \multirow{3}{*}{ Knowledge } & + & 92 & 4 & 96 \\
\hline & - & 4 & 0 & 4 \\
\hline & & 96 & 4 & 100 \\
\hline \multirow[t]{5}{*}{ Signed: Give Way } & \multicolumn{4}{|c|}{ Behaviour } \\
\hline & & + & - & \\
\hline & + & 100 & 0 & 100 \\
\hline & - & 0 & 0 & 0 \\
\hline & & 100 & 0 & 100 \\
\hline \multirow{6}{*}{$\begin{array}{l}\text { No signing: Right hand } \\
\text { rule } \\
\text { 4-way x-ing } \\
\quad \text { Knowledge }\end{array}$} & \multicolumn{4}{|c|}{ Behaviour } \\
\hline & & + & - & \\
\hline & & & & \\
\hline & + & 26 & 48 & 74 \\
\hline & - & 0 & 26 & 26 \\
\hline & & 26 & 74 & 100 \\
\hline \multirow{6}{*}{$\begin{array}{l}\text { No signing: Right hand } \\
\text { rule } \\
\text { 3-way x-ing } \\
\quad \text { Knowledge }\end{array}$} & \multicolumn{4}{|c|}{ Behaviour } \\
\hline & & + & - & \\
\hline & & & & \\
\hline & + & 5 & 52 & 57 \\
\hline & - & 0 & 43 & 43 \\
\hline & & 5 & 95 & 100 \\
\hline
\end{tabular}


even by a pedestrian. This problem of 'looking but not seeing' in road traffic has been, as far as we know, not really investigated except in the case of road signs (e.g., Johansson and Rumar 1966). This is a cognitive detection error which probably has a considerable motivational component.

A third detection error of cognitive aetiology may be caused by internal distraction. People are preoccupied by some personal problem to such an extent that their normal information search patterns are destroyed or they are looking without seeing.

Using the simple operator model oulined in figure 1, the main contributor to cognitive detection errors is the fact that detection behaviour in present road traffic too often has to be carried out at the conscious, planned level instead of in a natural, unconscious and automatic way, which is both faster and more effective.

In conclusion we may say that cognitive detection errors of the type discussed above are a result of a discrepancy between the road user model of the traffic environment and the real situation. This may lead to erroneous expectancies, or lack of expectation, which in turn may contribute to failure to detect the other road users in time to avoid a collision.

Are the more effective countermeasures against these classes of detection errors to be found in the cognitive domain (e.g., information, education, training), or are equally effective but simpler countermeasures to be found among perceptual enhancement (e.g., fluorescent colours, daytime running lights, flashing beacons)? This is the topic of the next section.

\section{Perceptual detection errors}

As we have noted above, our perceptual (visual) system is a product of ecological adaptation. Thanks to a functional perceptual system we have survived by early detection of our enemies and efficient detection of our prey; thanks to a functional perceptual system we have been able to detect mismatches between our predictions and expectations and reality. During the past few centuries humans have, to a large extent, left the old ecological environments and entered artifical activities like driving cars on modern roads. Thus our ecologically-developed and -designed perceptual systems have become partly obsolete. Typical examples are late or even failed detection in night traffic, or when vehicles approach in the periphery of the visual field. The situation has gradually changed in such a way that some road traffic situations now present important stimuli (other road users) below some of the thresholds of the visual system. These thresholds were developed and set during the evolutionary history of humankind, and proved to work superbly under the earlier demands that they were designed to meet. They are unfortunately inadequate in some contemporary road traffic conditions. In particular there are situations in which they do not offer adequately sensitive detection of oncoming motor vehicles.

\section{Vehicle colour}

Dahlstedt and Rumar (1973) carried out a study of cues used for detection of oncoming vehicles in rural traffic. Colour slides and verbal descriptions were taken at the moment of detection in real traffic. Their results show that brightness contrast (colour, silhouette, flashes, headlights) is the dominating single factor ( $>80 \%)$ during summer as well as winter. Colour contrast occurred in some cases at high levels of general illumination $(\sim 15 \%)$. Motion was the smallest single cause $(5-10 \%)$. When headlights (low beam) were on this was invariably the cause for detection. 
On the basis of these results, Dahlstedt and Rumar made some laboratory studies of the conspicuity of 16 various car colours with and without headlights against some common traffic backgrounds. Subjects were asked to detect 'the vehicle' on a colour picture projected for a very short time in front of them. Detection time was the criterion. The results showed that optimal colour for conspicuity changed with background. However, when the background was not the sky or a snow field, headlights on gave the same effect as the best colour. After these results, the study of relative discriminability of car colour was abandoned and all subsequent studies of vehicle conspicuity concerned vehicle lights.

\section{Vehicle lights}

Most studies of vehcile detection as a function of front light intensity have been carried out in central (foveal) vision (for a review see Rumar et al. 1989). The results from these studies indicate that, in central vision, even very low daytime running light (DRL) intensities $(<100 \mathrm{~cd}$ each) may increase vehicle conspicuity. Effectiveness of detection increases markedly with intensity, and even quite high intensities $(<5000 \mathrm{~cd}$ each) are very effective and cause no serious problem of glare. However there is some disagreement on this last point. Some argue that, if lights are to be acceptable at dawn and dusk, glare problems may occur, and they suggest a maximum value of 1000 $1500 \mathrm{~cd}$.

Rumar and his co-workers (Rumar et al. 1989) have, in several studies, systematically investigated the peripheral conspicuity of oncoming vehicles as a function of vehicle lighting intensity and ambient illumination. The results from these studies indicate that in broad daylight ( $>30001 \mathrm{x}$ sky illumination) the intensity corrresponding to an ordinary low beam (about $400 \mathrm{~cd}$ ) is needed to improve vehicle conspicuity in $30^{\circ}$ peripheral vision. In $60^{\circ}$ peripheral vision more than $1000 \mathrm{~cd}$ is needed to increase vehicle conspicuity.

In another study using $20^{\circ}$ peripheral vision, it was shown that, when the ambient illumination level decreases (dawn and dusk $<1000 \mathrm{~lx}$ sky illumination), considerably lower intensities are needed substantially to increase peripheral vehicle conspicuity: at $600 \mathrm{~lx}$ about $300 \mathrm{~cd}$, at $400 \mathrm{~lx}$ about $200 \mathrm{~cd}$ (see figure 2).

With regard to the colour of the light, the results indicate that in subjective evaluations observers say they find yellow or amber lights more conspicuous than white ones. However, in objective studies, colour (white and yellow) seems unimportant. Light intensity, rather than colour, determines detectability. From the legislative point of view, both colours could be accepted.

Other positive perceptual effects of lights on cars in daytime are:

- they are estimated to be closer than non-lighted cars;

- it is easier to determine the lateral (lane) position of a lighted car;

- it is easier to determine whether a car is moving if light is the signal.

Some negative effects of lights that have been studied are:

- smaller effect if everyone has them (the novelty effects disappear);

- worse for those not having them (effect of expectation and masking);

- glare in dawn and dusk periods (masking effects);

- increased petrol and bulb consumption (economy);

- special lights quickly lose their efficiency due to dirt, corrosion, bad aiming, etc. (durability).

All these negative effects exist but are judged to be minor and possible to overcome. 


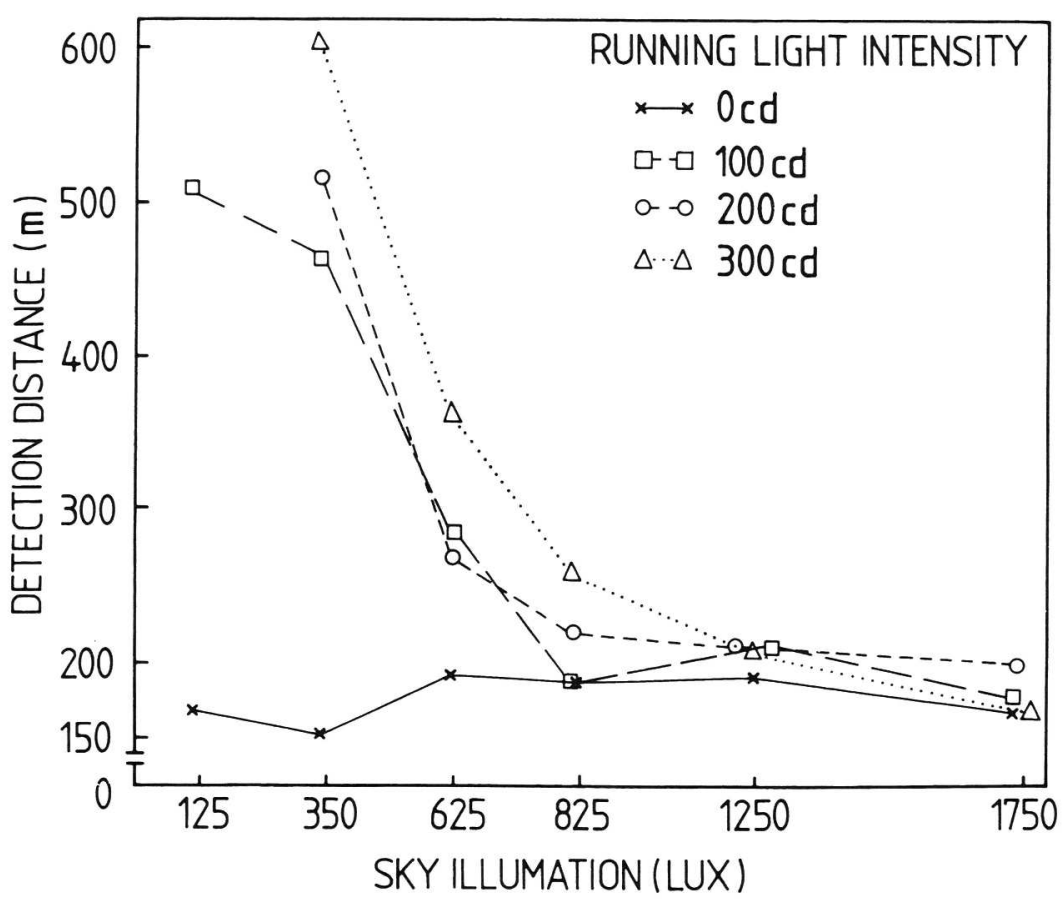

Figure 2. Peripheral $\left(20^{\circ}\right)$ detection distance $(\mathrm{m})$ of oncoming vehicles as a function of sky illumination (lux) and DRL intensity (cd).

\section{Accident evaluation}

Early studies in the US and Sweden gave positive results of lights on accident reduction, but these were not well controlled. Later better controlled studies in Finland, Sweden, the US, and Norway, however, have been carried out. They all support each other and present consistent effects. A review of these evaluation studies is given in Helmers (1988). Here we simply present a representative Swedish study (Andersson and Nilsson 1981). They used single-vehicle accidents and night-time accident as controls, thereby balancing for irrelevant factors that may have varied during the before and after periods (daytime running lights were made compulsory in Sweden in 1977). Table 2 gives the results.

The road users who seem to benefit most from lights on cars are pedestrians and cyclists. These groups probably use their peripheral vision more than drivers. Furthermore, these road users may have visual degradation which gives them a visual status that is lower than that of drivers, since they are not exposed to any statutory visual screening.

Table 2. The accident reduction of daytime collisions as an effect of introduction of DRL in Sweden 1977.

\begin{tabular}{lll}
\hline & Day & Night \\
\hline Single Acc & Control & Control \\
Collisions & $-13 \%$ & Control \\
Daytime & Head on & $-10 \%$ \\
Collisions & Angular & $-9 \%$ \\
Subgroups & Rear end & $-2 \%$ \\
& Car-bicycle & $-17 \%$ \\
& Car-pedestrian & $-21 \%$ \\
\hline
\end{tabular}




\section{Pedestrians in night traffic}

It is generally accepted that night driving is two or three times more hazardous than daylight driving, per $\mathrm{km}$ driven. However, since most driving is carried out during daylight hours, the absolute accident figures are generally higher for daylight illumination. Nevertheless, in many countries some types of accident, such as pedestrians being hit by cars, are more frequent even in absolute terms at night than during daylight. Night driving is a situation for which humans have not evolved, and in which our visual system proves inefficient.

Contrast sensitivity is drastically lowered at levels of night-time illumination. In addition to this basic handicap, other properties of the eye, such as glare sensitivity and night myopia, become especially important and critical in night-time traffic. The most critical situation is the meeting phase; both the initial stage on high beam and the final stage on low beam. During this meeting phase, visibility distance thresholds for dark objects (e.g., pedestrians) on the road are normally around $50 \mathrm{~m}$ and very seldom above $100 \mathrm{~m}$ (for a review, see Rumar 1976). From the safety point of view, at least $140 \mathrm{~m}$ is required. What countermeasures might be effective? Studies so far have produced the following results:

- driver training: limited improvement;

- road lighting: effective but expensive;

- ultraviolet lighting: a promising new technology which, however, requires fluorescent targets;

- polarized headlights: an earlier, effective idea, which, however, requires the interposition of filters between the oncoming polarized lights and the driver's eyes;

- electronic vision: probably the technology of the future (e.g. radar, infrared).

The most effective and inexpensive way to improve detection of pedestrians is to improve their night-time conspicuity by retroflective material. The effect of retroflective material has been shown in a series of studies (for a review, see Rumar 1976). The technical principles used (spheric or prismatic retroflection) mean that the contrast with the dark background as seen by the driver from behind the headlights is several hundred times higher than that of white cloth. Retroreflective materials thus compensate for the decreased contrast sensitivity of the eye in night traffic and provide an effective, fast and inexpensive countermeasure. In order to reach a visibility of $140 \mathrm{~m}$ the pedestrian chould be carrying retroreflective material with a reflective power of at least 300 CIL (see figure 3).

\section{Conclusions}

There is reason to believe that delayed detection of other road users is a main factor in road traffic collisions. We propose that these detection failures fall into two main categories: cognitive detection errors; and perceptual detection errors.

Cognitive detection errors are argued to be an effect of incomplete or erroneous road user models of the traffic environment and of the moving elements in this environment. This effect leads to inappropriate expectations which, in turn, result in late or even failed detections. Another way of describing the situation is to say that detection in present road traffic often has to be achieved by consciously directing the focus of attention. This is a slower and less effective detection process than the basic ecological, normal, unconscious, quick, and automatic detection. 


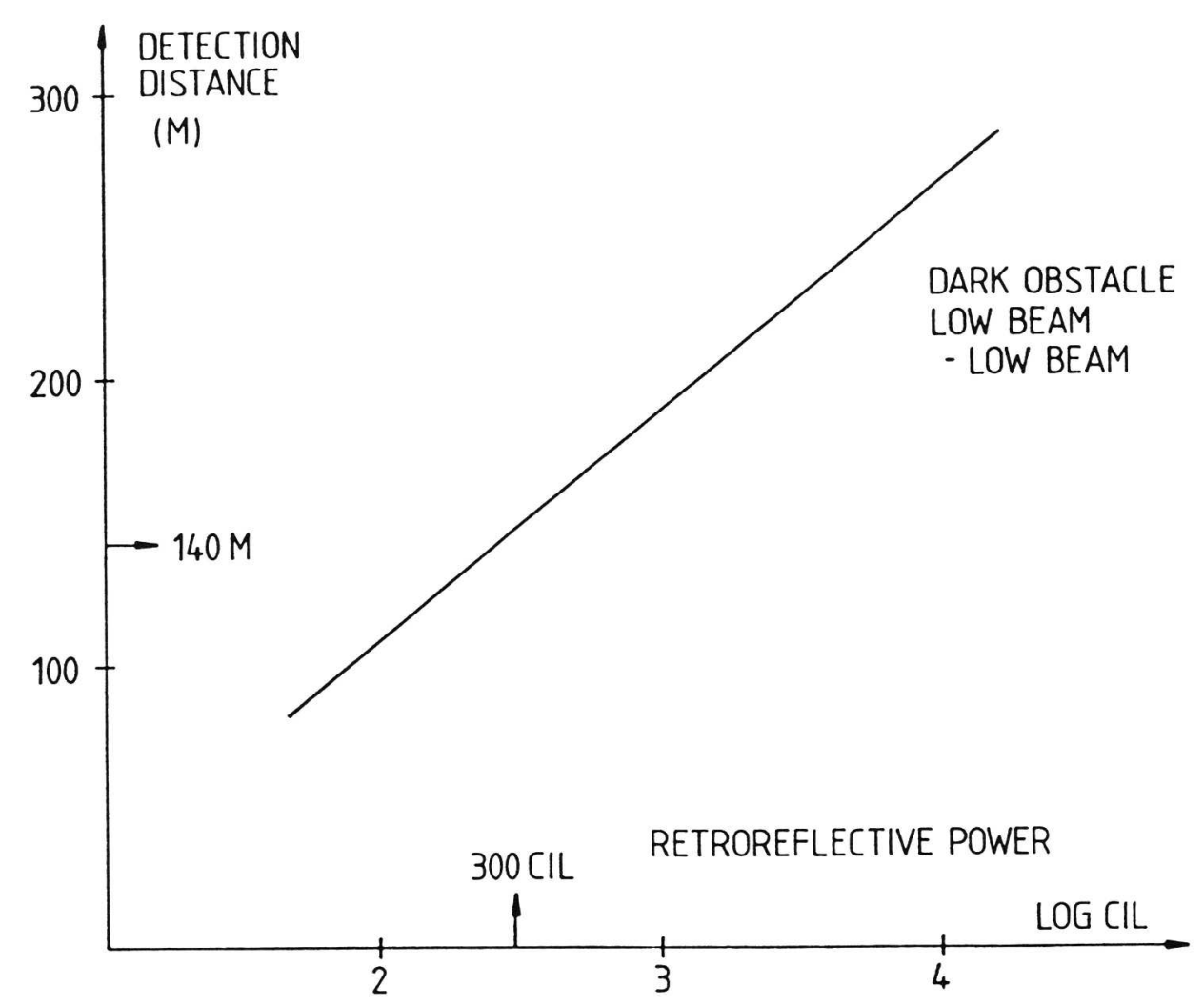

Figure 3. Outline of the relation between retroreflective power and driver detection distance for vehicles meeting at night.

It is argued that perceptual detection errors have a similar evolutionary history. Stimulus patterns which were essential for detection during our evolutionary history and which determined the development of our visual perceptual systems are not available in many contemporary road traffic situations. Peripheral sensitivity to movement is ineffective since the contours of our present 'enemies', i.e., cars, have no perceptible internal motion. They roll closer without any associated higher frequency movements, such as the leg movements of an animal predator. The contrast sensitivity of the eye is so impaired at lower levels of ambient illumination that other road users without lights are thus not detected early enough in night traffic.

With regard to the problem of countermeasures for detection errors, it seems comparatively inefficient to try to educate, inform, persuade, or train road users to improve their level and field of attention. By contrast, countermeasures involving stimulus enhancement have proved to be efficient both in experimental studies and in accident analyses. By improving the conspicuity of road users we seem to be able to compensate for both types of road traffic detection errors-cognitive as well as perceptual. However it is risky to focus all our efforts at countermeasures on improving detection by enhancement of stimuli conspicuity. If we continue to enhance conspicuity, we arrive at a point where the more powerful cues we have provided begin to compete with, and to mask each other. We know, for instance, that flashing lights are very conspicuous as long as there are only very few of them in the same visual scene. As soon as they increase in number they distract attention from each other.

Whilst perceptual detection problems are comparatively well studied, there is an obvious gap in knowledge concerning cognitive detection problems. Many of the hypotheses put forward by this paper therefore need to be tested in systematic empirical studies. 


\section{References}

Andersson, K., and Nilsson, G., 1981, The effects on accidents of compulsory use of running lights during daylight in Sweden. Report 208A, VTI, Linköping, Sweden.

DAHLSTEDT, S., and RUMAR, K., 1973, Vehicle colour and front conspicuity in some simulated rural traffic situations. Report, Department of Psychology, University of Uppsala, Sweden.

Helmers, G., 1988, Daytime running lights: a potent traffic safety measure? Report 333A, VTI, Linköping, Sweden.

HeLmers, G., and ÅBERG, L., 1978, Driver behaviour in intersections as related to priority rules and road design. Report 167, VTI, Linköping, Sweden.

JANSSEN, W. H., 1979, Routeplanning en geleiding: een literatuurstudie. Report IZF 1979 C-13, Institute for Perception TNO, Soesterberg, The Netherlands.

Johansson, G., and Rumar, K., 1966, Drivers and road signs, Ergonomics, 9 (1), 57-62.

RASMUSSEN, J., 1980, The human as a system component. In Human Interaction with Computers, edited by H. T. Smith and G. Green (Academic Press, London).

Rumar, K., 1976, Pedestrian safety in night driving. Proceedings of the International Conference on Pedestrian Safety, Haifa, Israel, 7A1-7A5.

Rumar, K., Dellby, L., Moore, D., Hitzemeyer, E., Reynolds, A., and White, J., 1989, Automobile daytime running lights (DRL), CIE TC-4.13 draft report.

TrEAT, J. R., 1980, A study of precrash factors involved in traffic accidents, HSRI 10/11, 6/1 Highway Safety Research Institute (HSRI), Ann Arbor, MI.

United Nations, 1986, Statistics of Road Traffic Accidents in Europe (United Nations, New York).

Au cours de ces deux ou trois dernières décennies, nous avons réussi, avec un certain succès, à réduire les blessures graves des occupants de voiture, grâce à la mise en oeuvre de techniques d'absorption des chocs; mais nous n'avons pas aussi bien réussi à réduire les risques de collision. Lorsqu'on demande à un conducteur pourquoi un accident est survenu, il répond très souvent qu'il avait vu trop tard l'autre usager pour éviter la collision. Cet article est consacré à l'étude de cette défaillance fondamentale qui consiste à ne pas percevoir à temps l'autre conducteur; on s'interroge sur le pourquoi de telles erreurs et comment elles pourraient être réduites. Une erreur de détection est fondamentale parce que sans détection, il ne peut y avoir ni traitement de l'information, ni prise de décision. Les deux causes les plus importantes d'une erreur de détection sont: (1) une défaillance de l'expectation cognitive illustrée par l'absence de scrutage pour apercevoir un autre usager ou par le défaut de regarder dans la direction appropriée. (2) Un problème de seuil perceptif illustré par la non-distinction du stimulus pertinent dans des niveaux trop bas d'éclairage ambiant ou dans des situations où des véhicules se déplacement dans le champ de vision périphérique du conducteur.

Während der letzten zwei oder drei Jahrzehnte waren wir dank der Verwendung von energieabsorbierenden Techniken recht erfolgreich mit der Verringerung von Verletzungen bei Autoinsassen. Jedoch waren wir bei der Verringerung des Risikos von Kollisionen nicht ebenso erfolgreich. Wenn Fahrer befragt wurden warum ein Unfall passierte, beklagen sie sich sehr oft, daß sie den anderen Verkehrsteilnehmer zu spät sahen, um eine Kollision zu verhindern. Diese Studie diskutiert den grundlegenden Fehler von Verkehrsteilnehmern, einen anderen Verkehrsteilnehmer nicht rechtzeitig zu sehen, warum solche Fehler geschehen und wie sie reduziert werden können.

Ein Wahrnehmungsfehler ist grundlegend, weil ohne Wahrnehmung kein Informations- und Entscheidungsprozeß stattfindet, der diesen Verkehrsteilnehmer berücksichtigt. Unter den vielen Ursachen für Wahrnehmungsfehler sind zwei der wichtigeren: Fehlen kognitiver Erwartung, welches deutlich wird durch die Schwäche, nach einer bestimmten Art von Verkehrsteilnehmern zu suchen oder in die zutreffende Richtung zu schauen; Schwierigkeiten mit Wahrnehmungsschwellen, welche durch Schwächen der Unterscheidung relevanter Stimuli bei geringer Umgebungshelligkeit oder in Situationen, wo Fahrzeuge im peripheren Gesichtsfeld des Verkehrsteilnehmers auftauchen, deutlich werden. 
